(2) Open Access Full Text Article

\title{
Spotlight on romiplostim in the treatment of children with chronic immune thrombocytopenia: design, development, and potential place in therapy
}

This article was published in the following Dove Press journal:

Drug Design, Development and Therapy

30 March 2017

Number of times this article has been viewed

\section{David Buchbinder \\ Diane Nugent \\ Loan Hsieh}

Division of Hematology, CHOC Children's Hospital and UC Irvine Medical Center, CA, USA
Correspondence: David Buchbinder Division of Hematology, CHOC Children's Hospital and UC Irvine Medical Center, I20I W. La Veta Avenue, Orange, CA 92868, USA $\mathrm{Tel}+\mathrm{I} 7145098459$

Fax + I $7 \mid 4509877$ |

Email dbuchbinder@choc.org

\begin{abstract}
Primary immune thrombocytopenia (ITP) is an autoimmune disorder characterized by isolated thrombocytopenia. In approximately one-third of cases, the duration of thrombocytopenia will extend beyond 12 months consistent with a diagnosis of chronic ITP. Minor bleeding manifestations are common in chronic ITP while severe or life-threatening bleeding complications are uncommon. Moreover, spontaneous resolution occurs in the majority of children with chronic ITP necessitating treatment in only those children with ongoing bleeding manifestations or impairment in health-related quality of life (HRQOL). The characterization of thrombopoietin (TPO) and remarkable advancements in our understanding of the pathophysiology of ITP has led to the development of a new class of agents, the TPO-receptor agonists that have documented efficacy in the amelioration of thrombocytopenia and bleeding manifestations in chronic ITP. Romiplostim is a second-generation TPO-receptor agonist that has undergone limited evaluation in the treatment of chronic ITP in children. Evolving data suggest that romiplostim may be a safe and effective agent in the treatment of chronic ITP in children. Additional data are needed to confirm its ability to increase platelet counts, decrease bleeding manifestation, and improve the HRQOL of children and caregivers impacted by chronic ITP.
\end{abstract}

Keywords: thrombocytopenia, chronic, thrombopoietin, childhood

\section{Introduction}

Primary immune thrombocytopenia (ITP) in children is defined as an autoimmune disorder characterized by isolated thrombocytopenia in the absence of other causes or disorders that are associated with thrombocytopenia. ${ }^{1}$ Current estimates suggest that the incidence of newly diagnosed ITP in children is between 1.9 and 6.4 per $10^{5}$ children/year. ${ }^{2}$ Newly diagnosed, "acute" ITP is defined as lasting $<3$ months, "persistent" lasting up to 12 months, and "chronic" lasting beyond 12 months in which a spontaneous remission is not achieved or in which patients do not achieve a response off therapy. ${ }^{1}$ Despite the fact that the vast majority of children with ITP will experience resolution, estimates suggest that one-third of children will demonstrate thrombocytopenia at 12 months post-diagnosis consistent with chronic ITP. ${ }^{3}$ Risk factors associated with the development of chronic ITP in children are numerous such as female gender, older age at presentation, a lack of preceding infection or vaccination, insidious onset, higher platelet counts at presentation, and the presence of antinuclear antibodies. ${ }^{4}$ Other biomarkers such as cytokines and gene expression profiles are currently being explored to better differentiate chronic ITP from those newly diagnosed cases that will not become chronic. ${ }^{5,6}$ As an example, genes involved in B-cell 
differentiation and the commitment of specific T-cell subsets are over-represented among individuals with chronic ITP when compared with acute ITP. Moreover, specific cytokines such as interleukin 4 are higher in individuals with chronic ITP when compared with those with acute ITP supporting the potential role of B-cell activation and antibody production as well as T-cell activation.

Among children with chronic ITP, minor bleeding issues such as petechiae, ecchymosis, epistaxis, and hematuria are frequently seen. ${ }^{3}$ Though infrequent, life-threatening bleeding such as intracranial hemorrhage can result in significant risk for morbidity and mortality. ${ }^{7}$ Treatments for individuals with chronic ITP are largely tailored to the needs of the patient and their family. ${ }^{8}$ Currently available therapeutic agents may provide a transient increase in platelet counts. This may be associated with diminished bleeding in some children. Other collateral benefits may be seen in some families such as less parental anxiety and greater support for children to participate in social activities. Therefore, the perceived benefits must be balanced against the potential risks of therapy as perceived by each individual patient and family. For those children with chronic ITP who experience bleeding and for those in whom health-related quality of life (HRQOL) is impaired, treatment is often considered. ${ }^{8}$ It is important to acknowledge that spontaneous remission is expected to occur for the majority of children with chronic ITP. ${ }^{3}$ Of the one-third of patients who continue to have thrombocytopenia at 12 months following diagnosis, one-quarter will have achieved a normal platelet count at 24 months following diagnosis. ${ }^{3}$

Treatments for chronic ITP largely overlap with the therapeutic agents utilized for the treatment of acute ITP ${ }^{8}$ Commonly chosen agents include intravenous immunoglobulin, anti-D immunoglobulin, and corticosteroids. ${ }^{9,10}$ The list of agents has continued to expand and now includes a variety of agents such as vincristine, danazol, mycophenolate mofetil, and dapsone utilized as monotherapy or in various combinations. ${ }^{11-13}$ Humanized monoclonal antibodies such as rituximab (anti-cluster of differentiation 20 antibody) are also options. Responses are only documented in approximately one-third of patients with only occasional minor toxicities such as serum sickness and infrequent serious adverse events such as infectious complications. ${ }^{14,15}$ Surgical options including splenectomy remain as options with robust responses documented in approximately three-quarters of patients and only infrequent serious adverse events such as sepsis and major bleeding. ${ }^{16}$ These therapeutic approaches are limited and may only result in transient improvements in platelet counts and associated bleeding. The thrombopoietin (TPO) receptor agonists represent a new therapeutic option for children with chronic ITP.

\section{Pathophysiology of chronic ITP}

The pathophysiology of chronic ITP is heterogeneous and complex. ${ }^{17}$ In chronic ITP, platelet membrane glycoproteins (GPs), become antigenic and stimulate the immune system to produce autoantibodies. The factors that initiate the production of autoantibodies directed against platelet antigens are unknown. The development of these autoantibodies against platelet GPs plays a central role in the pathogenesis of chronic ITP. The platelet-directed autoantibodies are more commonly directed against platelet GP IIb-IIIa and/or GPIb-IX. Many patients produce multiple antibodies secondary to the phenomenon known as epitope spreading. Once produced, autoantibodies bind to platelets, causing their destruction by either phagocytosis or possibly complement activation and subsequent lysis. Antibody-coated platelets may be cleared by Fc gamma receptor (Fc $\gamma \mathrm{R})$-bearing phagocytes. ${ }^{18}$ Specific isoforms of these receptors may be associated with the development of chronic ITP. In addition to the antibody-mediated destructive process, a perturbation in T-cell homeostasis also plays a role in the pathogenesis of chronic ITP. ${ }^{19}$ In chronic ITP, there is commonly a shift toward a Th1 response consistent with immune activation. Moreover, there may also be a decrease in the number and function of regulatory $\mathrm{T}$ cells. Many of these mechanisms (eg, FcyR binding and signaling) are under investigation as potential therapeutic targets. Platelet production is also suboptimal in chronic ITP patients. Megakaryocytes express GPIIb-IIIa and GPIb-IX, which are targets for autoantibodies. These autoantibodies inhibit megakaryocyte growth as documented by morphologically abnormal megakaryopoiesis and the ability of ITP plasma to inhibit megakaryopoiesis. Autoantibodies also promote apoptosis as documented by ultrastructural abnormalities in megakaryocytes in patients with ITP consistent with increased apoptosis. The suboptimal platelet production in ITP that is mediated by the presence of autoantibodies directed against platelet antigens provides support for the use of TPO mimetic agents in the treatment of children with chronic ITP.

\section{Design and development}

\section{Thrombopoietin}

TPO is a lineage-specific cytokine that serves as the major regulator of circulating platelet levels through its ability to stimulate the proliferation and maturation of committed hematopoietic progenitor cells and the subsequent production of megakaryocytes and platelets. ${ }^{20} \mathrm{TPO}$ is synthesized 
in the liver. It stimulates the proliferation and maturation of committed hematopoietic progenitor cells and the subsequent production of megakaryocytes and platelets via its interaction with the c-Mpl receptor which is constitutively expressed on hematopoietic progenitor cells, megakaryocytes, and platelets. TPO binds the distal part of the inactive TPO receptor that creates an activated receptor. Upon activation, a variety of downstream signaling events occur including activation of Janus kinase 2, signal transducer and activators of transcription 5 , the mitogen-activated protein kinase pathway as well as anti-apoptotic pathways which enhance cell survival, proliferation, and differentiation of megakaryocytes. A variety of mechanisms also exist to downregulate TPO signaling once the hormone binds to c-Mpl. The circulating concentration of TPO is regulated by the platelet and megakaryocytic mass. As expected, in patients with ITP, the level of TPO is typically normal or low. Efforts to identify TPO were unsuccessful until the early 90 s. In 1994, Lok et al made a scientific breakthrough in which they were able to clone and express murine TPO cDNA and stimulate platelet production in vivo. ${ }^{21}$

\section{First-generation thrombopoietin agonists}

This breakthrough cloning and expression of TPO paved the way for the development of TPO receptor agonists with the capability of increasing platelet counts in patients with thrombocytopenia. Two recombinant forms of TPO receptor agonists were synthesized and extensively studied including recombinant human TPO (rhTPO) and pegylated recombinant human megakaryocyte growth and development factor (PEG-rHuMGDF). ${ }^{22}$ The amino acid sequence of rhTPO was identical to that of endogenously produced TPO, produced in mammalian cells, and glycosylated. PEG-rHuMGDF, produced in Escherichia coli, included the receptor binding, 163 amino-terminal amino acids of endogenously produced TPO, conjugated to a polyethylene glycol moiety to increase its half-life in circulation. Both of these so-called "first-generation" TPO receptor agonists were extensively evaluated clinically in a variety of settings marked by thrombocytopenia. Despite potent stimulation of the production of megakaryocytes and platelets in various settings, PEG-rHuMGDF was paradoxically associated with the development of persistent thrombocytopenia in some individuals. Li et al provided further characterization of these individuals documenting that the thrombocytopenia was due to the development of antibodies to PEG-rHuMGDF which cross-reacted with and neutralized endogenous TPO. ${ }^{23}$ As a result, efforts focused on the identification of molecules that could provide stimulation of the c-Mpl receptor without stimulating the production of cross-reactive antibodies.

\section{Second-generation thrombopoietin agonists}

Screening of peptide libraries along with the conjugation of candidate peptides to various moieties to increase their half-life in circulation led to the identification of romiplostim, previously known as AMG-531. ${ }^{24}$ Romiplostim is a 60,000 D molecule which serves as a c-Mpl receptor agonist. It is a peptidobody consisting of two short peptides that are coupled to an Fc domain giving it four Mpl-binding sites. The peptides have no homology to TPO. Romiplostim is administered subcutaneously. The starting dosage of romiplostim is $1 \mu \mathrm{g} / \mathrm{kg}$ weekly with a maximum dose of $10 \mu \mathrm{g} / \mathrm{kg}$ weekly. It is cleared by endothelial neonatal Fc receptors and subsequently recycled and ultimately cleared by the reticuloendothelial system. ${ }^{25}$ Once it activates the c-Mpl receptor, there is activation of the aforementioned signal transduction pathways followed by the progressive increase of megakaryocyte proliferation and differentiation. ${ }^{26}$

\section{Potential place in therapy Adults}

Romiplostim was approved by the US Food and Drug Administration in 2008 for the treatment of chronic ITP in adults. Studies focusing on romiplostim in the treatment of chronic ITP in adults have been published with promising results. ${ }^{27,28}$ Romiplostim was associated with higher rates of a platelet response, lower rates of treatment failure and splenectomy, less bleeding, less need for rescue medications, and improved HRQOL. Serious toxicities aside from bleeding and hemorrhage have been recently re-evaluated utilizing data from 14 studies representing 994 patients treated with romiplostim and 1,520 patient-years of follow-up. ${ }^{29,30}$ The rates of thrombosis were 5.5 events per 100 patient-years and did not differ between recipients of romiplostim compared with placebo. The rates of hematologic malignancy were 0.5 events per 100 patient-years in the romiplostim group and 2.7 events per 100 patient-years in the placebo group. No non-hematologic malignancies related to romiplostim have been documented. The rate of cataract formation in the romiplostim group was 2.2 events per 100 patient-years compared with 0.9 events per 100 patient-years in the placebo group. The significance of this is unclear for a variety of reasons including the challenge of detecting cataracts, the short periods of romiplostim exposure, and the use of corticosteroids in some patients. Increased reticulin in the bone marrow has been documented with a rate of 1.3 events per 
100 patient-years. Neutralizing antibody formation directed against romiplostim has been documented; however, these antibodies did not impact endogenous TPO.

\section{Children}

Romiplostim has undergone limited evaluation in the treatment of chronic ITP in children (Table 1). Seven retrospective observational studies of children treated with romiplostim for chronic ITP have been published. Escudero Vilaplana et $\mathrm{al}^{31}$ reported on two children with chronic ITP who were treated with romiplostim. A 10 year old was followed for 27 weeks with maintenance of a complete response defined as a platelet count $>100,000 / \mu \mathrm{L}$ for 10 weeks and a partial response defined as a platelet count of $30,000-100,000 / \mu \mathrm{L}$ and a platelet count two times the baseline count for 4 weeks. The response was not maintained and romiplostim was stopped after 4 weeks at the maximum dose of $10 \mu \mathrm{g} / \mathrm{kg}$. The patient did receive concomitant pulses of corticosteroids. A 4 year old was followed for 39 weeks with maintenance of a complete response for 24 weeks. The patient also required concomitant corticosteroids and intravenous immunoglobulin. Marquinez-Alonso et $\mathrm{al}^{32}$ reported on four children with a mean age of 10.3 years treated with romiplostim for chronic ITP. The median treatment duration was 50.5 weeks. All the four patients achieved a response at least once during the course of treatment. A response was defined as a platelet count $>50,000 / \mu \mathrm{L}$ and doubling of the platelet count at the baseline on any scheduled visit, excluding platelet counts assessed within 8 weeks of rescue medications. Three patients achieved a durable response. A durable response was defined as platelet responses during 6 or more weeks of the last 8 weeks of treatment. Three patients received rescue medications. No adverse events were noted. Mokhtar et $\mathrm{al}^{33}$ reported on seven children with a median age of 5.5 years treated for a median duration of 12 weeks. Among those treated, one achieved a durable platelet response as defined by maintenance of a platelet count of $>50,000 / \mu \mathrm{L}$ for at least 6 consecutive weeks. Two patients achieved a transient response defined by maintenance of a platelet count of $>50,000 / \mu \mathrm{L}$ for at least four consecutive weeks. One patient achieved a weekly platelet response. Of the four patients who reported a variable response, two received concomitant corticosteroids. Seidel et $\mathrm{al}^{34}$ reported on seven children with a median age at diagnosis of 11 years treated with romiplostim for a median of 14 months. Increased platelet counts $(>50,000 / \mu \mathrm{L})$ were noted in six patients. Four patients with responses experienced a steep decline in platelet counts (often lower than before the initiation of therapy)
2-3 weeks after the last administration. Bleeding was only noted among the one individual who did not respond. Romiplostim was combined with various agents in the majority (71\%) of cases. No adverse events were recorded. Bone marrow exams were recorded for five patients and were normal. Pasquet et $\mathrm{al}^{35}$ reported on 10 children treated with romiplostim for a median of 9 months. One patient achieved a complete response and four patients achieved a partial response. A complete response was defined as a platelet count $>100,000 / \mu \mathrm{L}$ and the absence of bleeding. A partial response was defined as a platelet count between 30 and $100,000 / \mu \mathrm{L}$ and at least doubling of the baseline count along with the absence of bleeding. With respect to bleeding, five patients demonstrated clinical improvement with a disappearance of mucosal bleeding. Other adverse events such as thromboembolism, malignancy, rebound thrombocytopenia off therapy, and immunogenicity were absent. Ramaswamy et $\mathrm{al}^{36}$ reported on 21 children with a median age of 11.4 years treated with romiplostim at two institutions. Patients were treated for 6-44 months with 11 patients continuing to receive therapy. The majority of the patients $(86 \%)$ achieved the endpoints of maintenance of a platelet count of $>50,000 / \mu \mathrm{L}$ for two consecutive weeks, a platelet count $>20,000 / \mu \mathrm{L}$ higher than baseline, and a platelet count $>50,000 / \mu \mathrm{L}$ for $>50 \%$ of therapy. Bleeding symptoms were not noted although other adverse events reported included rash, nausea, and headaches. Other adverse events such as thromboembolism, malignancy, rebound thrombocytopenia off therapy, and immunogenicity were not documented. Bone marrow reticulin was assessed in 20 patients and was not increased aside from 1 patient that increased from MF1 (the presence of loose networks of reticulin with many intersections especially in perivascular areas) to MF2 (diffuse and dense increase in reticulin with extensive intersections occasionally with focal bundles of collagen and/or focal osteosclerosis) after 40 months of therapy. ${ }^{37}$ The largest and most recent observational study to date was reported by the Pediatric ITP Consortium of North America. ${ }^{38} \mathrm{~A}$ total of 79 children were treated for ITP including 60\% with chronic ITP using TPO receptor agonists. Romiplostim use was reported in 43 children. During the first 3 months of therapy, $86 \%$ of children treated with romiplostim achieved a platelet count of $>50,000 / \mu \mathrm{L}$. Of the children treated with TPO receptor agonists, $40 \%$ maintained a stable response, 15\% an intermittent response, and 13\% only an initial response. Adverse events reported included two thrombotic events and one patient with the formation of neutralizing antibodies. 


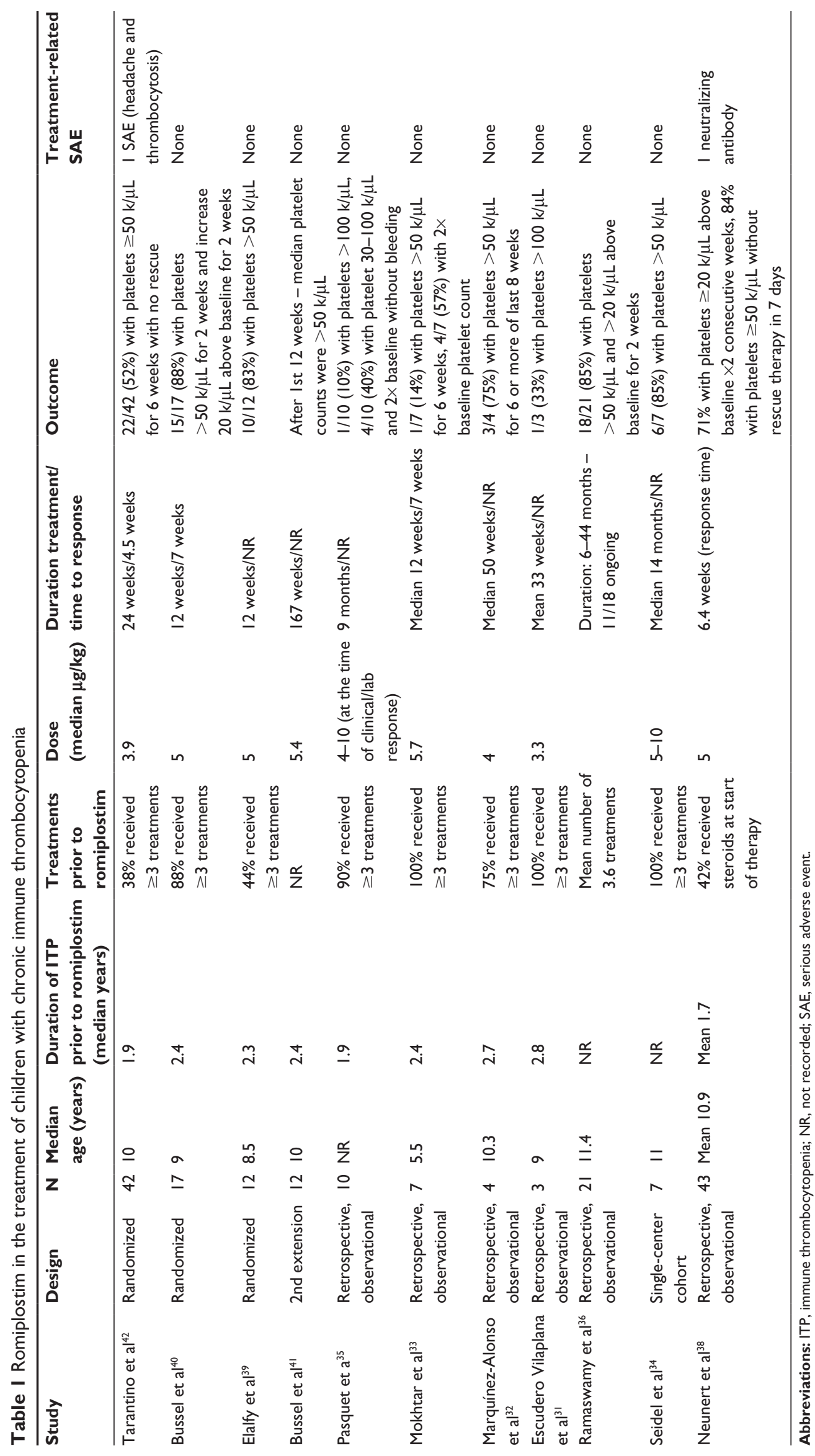


Three randomized controlled trials have been completed evaluating the efficacy and safety of romiplostim in children (Table 1). Elalfy et $\mathrm{al}^{39}$ completed a randomized, singleblinded, placebo-controlled trial at a single center. A total of 18 children with a median age of 8.5 years were randomized with 12 in the romiplostim group and 6 in the placebo group. Patients were treated for 12 weeks. Among the romiplostim group, $83.3 \%$ achieved the primary endpoint defined as the maintenance of a platelet count of $>50,000 / \mu \mathrm{L}$ compared to none in the placebo group. In addition to the aforementioned improvements in platelet counts in the romiplostim group, bleeding manifestations were improved compared to the placebo group. Hemorrhage (grades 3 and 2) was documented to improve from $33 \%$ at the baseline to $0 \%$ and from $50 \%$ at the baseline to $16.6 \%$, respectively. Rescue medications were necessary in $8.3 \%$ of patients treated with romiplostim versus $33.3 \%$ in the placebo group. Half of the participants in each treatment arm reported at least one adverse event with the most common being headaches and epistaxis. Other adverse events such as thromboembolism, malignancy, rebound thrombocytopenia off therapy, and immunogenicity were not documented. Bone marrow reticulin was not increased. Bussel et $\mathrm{al}^{40,41}$ completed a Phase I/II multicenter, randomized, double-blind, placebo-controlled study. A total of 22 children with a median age of 10 years were randomized with 17 in the romiplostim group and 5 in the placebo group. Patients were treated for 12 weeks and then offered participation in a 4-week pharmacokinetic extension study as well as continuation in a series of two open-label extension studies. Among the romiplostim group, 88\% achieved the primary endpoint defined as the maintenance of a platelet count of $>50,000 / \mu \mathrm{L}$ for 2 weeks consecutively compared to none in the placebo group. Despite the aforementioned improvements in platelet counts in the romiplostim group, bleeding manifestations were frequent. Hemorrhage was documented in $71 \%$ treated with romiplostim compared to $40 \%$ in the placebo group. All documented hemorrhages were minor mucosal bleeding events that did not require treatment. Rescue medications were necessary in $12 \%$ of patients treated with romiplostim versus $40 \%$ in the placebo group. Three patients $(18 \%)$ reported treatment-related adverse events including two patients with pyrexia and one patient with headache. Other adverse events such as thromboembolism, malignancy, worsening thrombocytopenia off therapy, and immunogenicity were not documented. Bone marrow reticulin was not assessed in any patient. Twenty patients were enrolled in the first extension study and 12 individuals were enrolled in the second extension study. The median romiplostim exposure across all three studies was 167 weeks. Over the three studies, the majority $(>90 \%)$ of patients were able to maintain median platelet counts $>50,000 / \mu \mathrm{L}$ after the first 12 weeks of the study. Despite the aforementioned improvements in platelet counts in the romiplostim group, bleeding manifestations were noted to be frequent. Hemorrhage was documented in $77 \%$ of patients treated with romiplostim. All documented hemorrhages were noted to be minor mucosal bleeding events, which did not require treatment with the exception of two patients. Rescue medications were necessary in $36 \%$ of patients treated with romiplostim. Treatment-related adverse events were documented in $27 \%$ of patients. Other adverse events such as thromboembolism, malignancy, worsening thrombocytopenia off therapy, and immunogenicity were not documented. Bone marrow reticulin was not assessed in any patient. Thrombocytosis was noted in $50 \%$ of patients; however, this was felt to be a minor issue, which resolved with further titration of the medication. Tarantino et $\mathrm{al}^{42}$ completed a larger Phase III multicenter, randomized, double-blind, placebo-controlled study. A total of 62 children were randomized with 42 in the romiplostim group and 20 in the placebo group. Patients were treated for 24 weeks with a median average dose of $3.9 \mu \mathrm{g} / \mathrm{kg}$. Among the romiplostim group, 52\% achieved the primary endpoint of a durable platelet response defined as the maintenance of weekly platelet count of $>50,000 / \mu \mathrm{L}$ in 6 or more of the final 8 weeks of study compared to $10 \%$ in the placebo group. An overall platelet response defined as $>4$ weeks with platelet count of $>50,000 / \mu \mathrm{L}$ during the period from 2 to 25 weeks of treatment was documented in $71 \%$ of the romiplostim group versus $20 \%$ in the placebo group. Post-hoc analysis suggested that younger children (1-6 years of age) were less responsive with $38 \%$ demonstrating a durable platelet response compared to $56 \%$ in the older age groups. Despite the aforementioned improvements in platelet counts in the romiplostim group, bleeding manifestations were equally frequent between the two groups. Hemorrhage was documented in $83 \%$ treated with romiplostim compared to $74 \%$ in the placebo group. Posthoc analysis of bleeding suggested that duration adjusted bleeding rates and those with higher grade bleeding (common terminology criteria for adverse events [CTCAE] grade II or higher) were less in the romiplostim group. All documented hemorrhages were minor mucosal bleeding events which did not require treatment. Rescue medication use was similar; however, post-hoc analysis of rescue medication use suggested that duration adjusted rates and those requiring rescue medication use for higher grade bleeding (CTCAE 
grade II or higher) were less in the romiplostim group. Only one participant reported treatment-related adverse events including headache and thrombocytosis. Other adverse events such as thromboembolism and immunogenicity were not documented. Bone marrow reticulin was assessed in only one patient.

\section{Health-related quality of life}

In addition to the aforementioned signs and symptoms of chronic ITP is the notion that the disease, its treatment, and associated sequelae may impact children and their parents with respect to physical, mental, emotional, and social health domains. Greater emphasis has been placed on these domains which are captured by the multidimensional concept of HRQOL. A disease-specific HRQOL instrument for children with ITP, the Kids' ITP Tools (KIT), has been developed and assessed with respect to its psychometric properties. There are three versions of the KIT including a child self-report version (for children $\geq 7$ years), a parent proxy-report version (for children $<7$ years), and a parent impact version to assess parental burden associated with ITP. Each KIT version contains 26 items that are summated to form a single score (with a range from 0 to 100). Higher KIT scores in the self/proxy-report version and parent impact version reflect more robust HRQOL in a child with ITP and less parental burden, respectively. The KIT has been validated and cross-culturally adapted for various countries such as France, Germany, and the UK. ${ }^{43,44}$ Moreover, the KIT has been incorporated into aforementioned clinical trials. The ability to obtain HRQOL data from children and parents impacted by chronic ITP will help ensure that the impact of chronic ITP and its treatments are understood in ways that extend beyond platelet numbers and bleeding scores.
These data ensure that valid inferences are made with respect to the efficacy of treatments including new agents such as romiplostim.

The effects of romiplostim on HRQOL in children with chronic ITP were first investigated using the KIT (Table 2). Klaassen et $\mathrm{al}^{45}$ embedded KIT assessments as part of an aforementioned randomized placebo-controlled study. A total of 22 children were assessed including 17 in the romiplostim group and 5 in the placebo group. KIT assessments were completed at weeks 1, 5, and 13. Statistically significant improvements were noted in parental impact in the romiplostim group when compared to the placebo group at week $13(24.0 \pm 17.1$ versus $-6.1 \pm 8.4 ; P=0.008)$. Although parent proxy-reports suggested an improvement in HRQOL among those treated with romiplostim, no statistically significant difference was noted in child self-report scores or parent proxy-report scores by time point or by the treatment group. Mathias et $\mathrm{al}^{46}$ completed a similar assessment of HRQOL among children with chronic ITP by also embedding KIT assessments as part of an aforementioned randomized placebo-controlled study. In this study, a total of 62 children were assessed including 42 in the romiplostim group and 20 in the placebo group. KIT assessments were completed at baseline, weeks 8,16 , and 25 . KIT score changes for child self-report and parent proxy-report did not differ by the treatment group; however, statistically significant improvements were noted among parent impact scores in the romiplostim group when compared to the placebo group. Statistically significant improvements were noted from baseline for both groups at weeks 16 and 25. These data suggest that romiplostim appears to reduce the burden of chronic ITP which is felt by parents. It is unclear if the use of romiplostim is associated with an improvement in

Table 2 Romiplostim in the treatment of children with chronic immune thrombocytopenia and health-related quality of life

\begin{tabular}{|c|c|c|c|c|c|c|c|}
\hline Study & Design & $\mathbf{N}$ & $\begin{array}{l}\text { Median age } \\
\text { (years) }\end{array}$ & $\begin{array}{l}\text { Duration of } \\
\text { ITP prior to } \\
\text { romiplostim }\end{array}$ & $\begin{array}{l}\text { Median number } \\
\text { of treatments }\end{array}$ & $\begin{array}{l}\text { Length of } \\
\text { treatment } \\
\text { (weeks) }\end{array}$ & Outcome (KIT scores) \\
\hline Tarantino et $\mathrm{al}^{42}$ & Randomized & 42 & 10 & 1.9 years & $\begin{array}{l}12 \% \text { other } \\
\text { concommitant } \\
\text { therapy at baseline }\end{array}$ & 24 & $\begin{array}{l}\text { No difference in KIT scores - child self, } \\
\text { parent proxy, or parent impact. Parent } \\
\text { impact scores improved in mixed effect }\end{array}$ \\
\hline Mathias et $\mathrm{al}^{46}$ & Randomized & 42 & Mean 9.7 years & Mean 3 years & $\begin{array}{l}38 \% \text { received } \geq 3 \\
\text { treatments }\end{array}$ & 24 & $\begin{array}{l}\text { KIT scores - self/proxy and parent } \\
\text { impact - greater reduction in parent } \\
\text { burden from baseline w/romiplostim } \\
\text { (compared with placebo) }-P=0.015\end{array}$ \\
\hline Klaassen et $\mathrm{al}^{45}$ & Randomized & 17 & 9 & 2.4 years & $\begin{array}{l}94 \% \text { with prior } \\
\text { treatment }\end{array}$ & 12 & $\begin{array}{l}\text { KIT scores - self/proxy and parent } \\
\text { impact - greater reduction in parent } \\
\text { burden from baseline w/romiplostim } \\
\text { (compared with placebo) }-P=0.008\end{array}$ \\
\hline
\end{tabular}

Abbreviations: ITP, immune thrombocytopenia; KIT, kids' ITP tools. 
HRQOL among children. The aforementioned studies were not powered to be able to assess the impact of romiplostim on changes in HRQOL; therefore, it is imperative that additional data be sought employing prospective studies with larger samples sizes.

\section{Future}

Evidence suggests that chronic ITP is associated with risk for morbidity and impairment in HRQOL among children. Commonly used therapeutic agents in children with chronic ITP are limited in number and efficacy. Moreover, many commonly used agents have a spectrum of toxicities. TPO receptor agonists represent a new therapeutic option in the treatment of children with chronic ITP. Although not conclusive, the available data suggest that treatment with romiplostim may be beneficial. Limited data document that romiplostim may be able to increase platelet counts and lessen the burden of bleeding manifestations in some children with chronic ITP. Responses to romiplostim vary widely in magnitude and duration and the ability to predict children who will respond robustly is not available at this time. In addition to a need for frequent titration in some patients, bleeding manifestations continue to require the use of rescue medications in some patients. Important questions remain with respect to the efficacy and longterm safety of romiplostim in children with chronic ITP. The potential benefit of romiplostim as it relates to patient reported outcomes including HRQOL is also unknown. Although serious adverse events are uncommon in children treated with romiplostim, we must continue to evaluate more fully the long-term safety of romiplostim. Future studies must focus on documenting the long-term safety of romiplostim. As an example, the collection of bone marrow data should be considered to evaluate for risks of myelofibrosis. Additional efficacy data are also desperately needed. This will require robust study designs incorporating adequate sample sizes. Cost-effectiveness and patient reported outcome measures such as HRQOL as well as parent and family impact must also be incorporated into these future studies. These data will help us better clarify the role romiplostim should play in the care of children with chronic ITP.

\section{Disclosure}

L Hsieh serves as a member of an AMGEN Advisory Committee. The other authors report no conflicts of interest in this work.

\section{References}

1. Rodeghiero F, Stasi R, Gernsheimer T, et al. Standardization of terminology, definitions and outcome criteria in immune thrombocytopenic purpura of adults and children: report from an international working group. Blood. 2009;113(11):2386-2393.

2. Terrell DR, Beebe LA, Vesely SK, Neas BR, Segal JB, George JN. The incidence of immune thrombocytopenic purpura in children and adults: a critical review of published reports. Am J Hematol. 2010;85(3): 174-180.

3. Neunert CE, Buchanan GR, Imbach P, et al; Intercontinental Cooperative ITP Study Group Registry II Participants. Bleeding manifestations and management of children with persistent and chronic immune thrombocytopenia: data from the Intercontinental Cooperative ITP Study Group (ICIS). Blood. 2013;121(22):4457-4462.

4. Heitink-Pollé KM, Nijsten J, Boonacker CW, de Haas M, Bruin MC. Clinical and laboratory predictors of chronic immune thrombocytopenia in children: a systematic review and meta-analysis. Blood. 2014;124(22): 3295-3307.

5. Jernås M, Hou Y, Strömberg Célind F, et al. Altered cytokine levels in pediatric ITP. Platelets. 2015;26(6):589-592.

6. Jernås $\mathrm{M}, \mathrm{Hou} \mathrm{Y}$, Strömberg Célind $\mathrm{F}$, et al. Differences in gene expression and cytokine levels between newly diagnosed and chronic pediatric ITP. Blood. 2013;122(10):1789-1792.

7. Psaila B, Petrovic A, Page LK, Menell J, Schonholz M, Bussel JB. Intracranial hemorrhage $(\mathrm{ICH})$ in children with immune thrombocytopenia (ITP): study of 40 cases. Blood. 2009;114(23):4777-4783.

8. Neunert C, Lim W, Crowther M, Cohen A, Solberg L Jr, Crowther MA; American Society of Hematology. The American Society of Hematology 2011 evidence-based practice guideline for immune thrombocytopenia. Blood. 2011;117(16):4190-4207.

9. El Alfy MS, Mokhtar GM,El-Laboudy MA, Khalifa AS. Randomized trial of anti-D immunoglobulin versus low-dose intravenous immunoglobulin in the treatment of childhood chronic idiopathic thrombocytopenic purpura. Acta Haematol. 2006;115(1-2):46-52.

10. Hedlund-Treutiger I, Henter JI, Elinder G. Randomized study of IVIg and high-dose dexamethasone therapy for children with chronic idiopathic thrombocytopenic purpura. J Pediatr Hematol Oncol. 2003; 25(2):139-144.

11. Miano M, Ramenghi U, Russo G, et al. Mycophenolate mofetil for the treatment of children with immune thrombocytopenia and Evans syndrome. A retrospective data review from the Italian association of paediatric haematology/oncology. Br J Haematol. 2016;175(3): 490-495.

12. Patel AP, Patil AS. Dapsone for immune thrombocytopenic purpura in children and adults. Platelets. 2015;26(2):164-167.

13. Boruchov DM, Gururangan S, Driscoll MC, Bussel JB. Multiagent induction and maintenance therapy for patients with refractory immune thrombocytopenic purpura (ITP). Blood. 2007;110(10):3526-3531.

14. Liang Y, Zhang L, Gao J, Hu D, Ai Y. Rituximab for children with immune thrombocytopenia: a systematic review. PLoS One. 2012;7(5): e36698.

15. Cooper N, Bussel JB. The long-term impact of rituximab for childhood immune thrombocytopenia. Curr Rheumatol Rep. 2010;12(2): 94-100.

16. Ahmed R, Devasia AJ, Viswabandya A, et al. Long-term outcome following splenectomy for chronic and persistent immune thrombocytopenia (ITP) in adults and children: splenectomy in ITP. Ann Hematol. 2016;95(9):1429-1434.

17. Nugent D, McMillan R, Nichol JL, Slichter SJ. Pathogenesis of chronic immune thrombocytopenia: increased platelet destruction and/or decreased platelet production. Br J Haematol. 2009;146(6):585-596.

18. Nishimoto T, Okazaki Y, Numajiri M, Kuwana M. Mouse immune thrombocytopenia is associated with Th1 bias and expression of activating Fc $\gamma$ receptors. Int J Hematol. Epub 2016 Dec 27.

19. Yazdanbakhsh K. Imbalanced immune homeostasis in immune thrombocytopenia. Semin Hematol. 2016;53(Suppl 1):S16-S19. 
20. Kaushansky K. Molecular mechanisms of thrombopoietin signaling. J Thromb Haemost. 2009; 7(Suppl 1):235-238.

21. Lok S, Kaushansky K, Holly RD, et al. Cloning and expression of murine thrombopoietin cDNA and stimulation of platelet production in vivo. Nature. 1994;369(6481):565-568.

22. Kuter DJ, Begley CG. Recombinant human thrombopoietin: basic biology and evaluation of clinical studies. Blood. 2002;100(10):3457-3469.

23. Li J, Yang C, Xia Y, et al. Thrombocytopenia caused by the development of antibodies to thrombopoietin. Blood. 2001;98(12):3241-3248.

24. Molineux G, Newland A. Development of romiplostim for the treatment of patients with chronic immune thrombocytopenia: from bench to bedside. Br J Haematol. 2010;150(1):9-20.

25. Yang BB, Doshi S, Arkam K, Franklin J, Chow AT. Development of romiplostim for treatment of primary immune thrombocytopenia from a pharmacokinetic and pharmacodynamic perspective. Clin Pharmacokinet. 2016;55(9):1045-1058.

26. Currao M, Balduini CL, Balduini A. High doses of romiplostim induce proliferation and reduce proplatelet formation by human megakaryocytes. PLoS One. 2013;8(1):e54723.

27. Kuter DJ, Bussel JB, Lyons RM, et al. Efficacy of romiplostim in patients with chronic immune thrombocytopenic purpura: a doubleblind randomised controlled trial. Lancet. 2008;371(9610):395-403.

28. Kuter DJ, Bussel JB, Newland A, et al. Long-term treatment with romiplostim in patients with chronic immune thrombocytopenia: safety and efficacy. Br J Haematol. 2013;161(3):411-423.

29. Rodeghiero F, Stasi R, Giagounidis A, et al. Long-term safety and tolerability of romiplostim in patients with primary immune thrombocytopenia: a pooled analysis of 13 clinical trials. Eur J Haematol. 2013;91(5): 423-436.

30. Cines DB, Gernsheimer T, Wasser J, et al. Integrated analysis of longterm safety in patients with chronic immune thrombocytopaenia (ITP) treated with the thrombopoietin (TPO) receptor agonist romiplostim. Int J Hematol. 2015;102(3):259-270.

31. Escudero Vilaplana V, Aragonés JH, Fernández-Llamazares CM, Bieler CB, Rodríguez SM, Sáez MS. Use of romiplostim for primary immune thrombocytopenia in children. Pediatr Hematol Oncol. 2012; 29(2):197-205.

32. Marquínez-Alonso I, Escudero-Vilaplana V, Pernía S, Beléndez Bieler C, Fernández-Llamazares CM, Sanjurjo-Sáez M. The treatment for primary immune thrombocytopenia with romiplostim in adult and paediatric patients: use experience at a Spanish university hospital. J Clin Pharm Ther. 2014;39(4):376-382.

33. Mokhtar GM, Tantawy AA, El Sherif NH. Romiplostim therapy in children with unresponsive chronic immune thrombocytopenia. Platelets. 2012;23(4):264-273.

34. Seidel MG, Urban C, Sipurzynski J, Beham-Schmid C, Lackner H, Benesch M. High response rate but short-term effect of romiplostim in paediatric refractory chronic immune thrombocytopenia. Br J Haematol. 2014;165(3):419-421.
35. Pasquet M, Aladjidi N, Guiton C, et al; Centre de Référence National des Cytopénies Auto-immunes de l'Enfant (CEREVANCE). Romiplostim in children with chronic immune thrombocytopenia (ITP): the French experience. Br J Haematol. 2014;164(2):266-271.

36. Ramaswamy K, Hsieh L, Leven E, Thompson MV, Nugent D, Bussel JB. Thrombopoietic agents for the treatment of persistent and chronic immune thrombocytopenia in children. J Pediatr. 2014;165(3): 600-605.e4

37. Thiele J, Kvasnicka HM, Facchetti F, Franco V, van der Walt J, Orazi A. European consensus on grading bone marrow fibrosis and assessment of cellularity. Haematologica. 2005;90(8):1128-1132.

38. Neunert C, Despotovic J, Haley K, et al; Pediatric ITP Consortium of North America (ICON). Thrombopoietin receptor agonist use in children: data from the pediatric ITP consortium of North America ICON2 Study. Pediatr Blood Cancer. 2016;63(8):1407-1413.

39. Elalfy MS, Abdelmaksoud AA, Eltonbary KY. Romiplostim in children with chronic refractory ITP: randomized placebo controlled study. Ann Hematol. 2011;90(11):1341-1344.

40. Bussel JB, Buchanan GR, Nugent DJ, et al. A randomized, double-blind study of romiplostim to determine its safety and efficacy in children with immune thrombocytopenia. Blood. 2011;118(1):28-36.

41. Bussel JB, Hsieh L, Buchanan GR, et al. Long-term use of the thrombopoietin-mimetic romiplostim in children with severe chronic immune thrombocytopenia (ITP). Pediatr Blood Cancer. 2015;62(2): 208-213.

42. Tarantino MD, Bussel JB, Blanchette VS, et al. Romiplostim in children with immune thrombocytopenia: a phase 3, randomised, double-blind, placebo-controlled study. Lancet. 2016;388(10039):45-54.

43. Klaassen RJ, Blanchette VS, Barnard D, et al. Validity, reliability, and responsiveness of a new measure of health-related quality of life in children with immune thrombocytopenic purpura: the Kids' ITP Tools. J Pediatr. 2007;150(5):510-515, 515.e1.

44. Klaassen RJ, Blanchette V, Burke TA, et al. Quality of life in childhood immune thrombocytopenia: international validation of the kids' ITP tools. Pediatr Blood Cancer. 2013;60(1):95-100.

45. Klaassen RJ, Mathias SD, Buchanan G, et al. Pilot study of the effect of romiplostim on child health-related quality of life (HRQoL) and parental burden in immune thrombocytopenia (ITP). Pediatr Blood Cancer. 2012;58(3):395-398.

46. Mathias SD, Li X, Eisen M, Carpenter N, Crosby RD, Blanchette VS. A phase 3, randomized, double-blind, placebo-controlled study to determine the effect of romiplostim on health-related quality of life in children with primary immune thrombocytopenia and associated burden in their parents. Pediatr Blood Cancer. 2016;63(7):1232-1237.

\section{Publish your work in this journal}

Drug Design, Development and Therapy is an international, peerreviewed open-access journal that spans the spectrum of drug design and development through to clinical applications. Clinical outcomes, patient safety, and programs for the development and effective, safe, and sustained use of medicines are the features of the journal, which

\section{Dovepress}

has also been accepted for indexing on PubMed Central. The manuscript management system is completely online and includes a very quick and fair peer-review system, which is all easy to use. Visit http://www.dovepress.com/testimonials.php to read real quotes from published authors. 